\title{
Variations of the Dose Distribution Between CT- and CBCT-based Plans for Oropharyngeal Cancer
}

\author{
MASAKAZU OTSUKA ${ }^{1 *}$, HAJIME MONZEN ${ }^{1,2^{*}}$, KAZUKI ISHIKAWA ${ }^{2}$, HIROSHI DOI $^{1}$, \\ KENJI MATSUMOTO $^{1}$, MIKOTO TAMURA ${ }^{1,2}$ and YASUMASA NISHIMURA ${ }^{2}$ \\ ${ }^{1}$ Department of Medical Physics, Graduate School of Medical Sciences, Kindai University, Osakasayama, Japan; \\ ${ }^{2}$ Department of Radiation Oncology, Faculty of Medicine, Kindai University, Osakasayama, Japan
}

\begin{abstract}
Background/Aim: The parotid glands in the head and neck are organs at risks (OARs) adjacent to high dose region and dose of OARs might be increased during the course of radiotherapy. The influence factors of the dose distribution for the parotid glands were investigated in terms of weight loss and mandibular rotation for head and neck cancers treated with volumetric modulated arc therapy (VMAT). Patients and Methods: Ten oropharyngeal cancer patients $(O P C)$ who underwent VMAT were enrolled. The dose volume histogram (DVH) parameters of the parotid glands and planning target volume (PTV) were compared between the planning computed tomography $(C T)$ and the on board imager (OBI) at 1, 5, 10, 15, and 20 fractions. Results: The variation of dose distribution in PTV was not observed in both factors. The relationship between the mandibular rotation and dose difference for the right and left parotid glands (linear regression, $r^{2}=0.1577$ and -0.689 ) showed a slighty stronger correlation with dose difference than the weight loss (linear regression, $r^{2}=-0.079$ and -0.547). Conclusion: The mandibular rotation tends to have a large influence on dose distribution of the parotid glands for head and neck cancers treated with VMAT.
\end{abstract}

Intensity modulated radiation therapy (IMRT) plays a critical role in the management of head and neck cancer patients (1). IMRT can maximize tumor coverage and/or sparing of organs at risks (OARs) by generating a steep dose gradient, and can thereby lead to a potential increase in the

This article is freely accessible online.

Correspondence to: Hajime Monzen, Ph.D., Department of Medical Physics, Graduate School of Medical Sciences, Kindai University, 377-2 Ohnohigashi, Osakasayama, Osaka 589-8511, Japan. Tel: +81 0723660221, Fax: +81 0723650206, e-mail: hmon@med.kindai.ac.jp

Key Words: VMAT, head and neck cancer, OARs, weight loss, setup-error. therapeutic index $(2,3)$. Other parameters, such as fractional anatomical changes, tumor shrinkage, nodal/glandular volume change, weight loss, and geometric variations, which can all occur during a typical 6-7-weeks treatment course $(4,5)$. A two-step IMRT method used as an adaptive radiation therapy scheme could allow modification of dosing to accommodate changes in body contour, target volumes, and organs at risk during IMRT (6-8). Adaptive radiation matching a change in dose with the patient's condition during treatment is, therefore, important. Cone beam computed tomography (CBCT) can be used to monitor the dose distribution during treatment and confirm the setup (9). Using CBCT obtained from the on-board imager (OBI), the patient's contour can be delineated and its shape and extent changes can be determined using deformable image registration (DIR) from original planning (9-11). For head and neck cancer patients, weight loss and setup accuracy are important, as these influence the dose distribution during IMRT (12-14). Furthermore, setup errors in the neck region of patients are generally greater compared to those occurring in the head region during the course of radiotherapy (15).

In this study, we investigated dose change, weight loss, and setup error (mandibular rotation) in the parotid gland, and used CBCT-based dose calculations to evaluate their influence on the dose distribution for oropharyngeal cancer (OPC) radiotherapy.

\section{Patients and Methods}

Patient characteristics and treatment methods. This retrospective study was approved by our institutional ethics committee (approval number:29-124), and all patients provided an informed written consent for volumetric modulated arc therapy (VMAT).

Ten consecutive patients who were treated for OPC using a twostep VMAT method combined with concurrent chemotherapy between November 2015 and August 2016 were evaluated. The tumor and treatment characteristics are shown in Table I.

The technique for two-step VMAT for OPC and the dose constrains have previously been described in detail (16). Briefly, all 
patients were treated with whole neck VMAT to a total of 46-50 Gy in 23-25 fractions as the initial plan, followed by a boost VMAT limited to the high-risk clinical target volume (CTV) of a total dose of 60-70 Gy over 30-35 fractions. All patients were immobilized with a thermoplastic mask covering the head, neck, and shoulders (Fibreplast Head \& Shoulder Portrait S-Frame thermoplastic based system; Q-FIX, PA, USA). All treatment planning data for the VMAT were calculated by inverse planning using a commercial treatment-planning system (Eclipse ver.13.6, Varian Medical Systems Inc, CA, USA). The VMAT consisted of 2 arcs. Dose constraints for the VMAT planning used at our institution are described in Table II.

Weekly CBCT and CBCT contouring. All patients were treated by VMAT with weekly CBCT for setup error correction. All images were analyzed online using the Varian On-board Imaging System software (Eclipse) was used to register the planning computed tomography (CT) to the $\mathrm{CBCT}(1,5,10,15$, and 20 fractions) by automatic bone matching. The Planning CT images were reconstructed with a resolution of $0.98 \times 0.98 \times 2.0 \mathrm{~mm}$ along the $\mathrm{x}$, $\mathrm{y}$, and $\mathrm{z}$ directions respectively. All CBCT images were acquired at a resolution of $0.91 \times 0.91 \times 2.0 \mathrm{~mm}$ before the radiation treatment for each fraction. The size of axial images for both planning CT and CBCT was $512 \times 512$ pixels. There were 88 slices in each CBCT scan, and the number of slices in the planning $\mathrm{CT}$ images ranged from 221 to 311 . A total of 20 planning CTs and 100 CBCTs were used in this study. The default parameter settings for the acquisition of the CBCT images were $100 \mathrm{kV}$ and $120 \mathrm{mAs}$. Using SmartAdapt ${ }^{\circledR}$ DIR software (Varian Medical Systems Inc., Palo Alto, CA, USA), the original planning target volumes (PTVs), CTVs, OARs (parotid glands, spinal cord, and brain stem) and external body contours were propagated to each CBCT for treatment re-planning, taking into account organ deformation (10). The patient's contours were deformed using DIR software and were confirmed by experienced radiation oncologists who were blinded to all other patient and treatment information in this study. The original plan was then copied over to the CBCT images, with the contours deformed for recalculation.

A CT electron density calibration curve was obtained to calculate the dose using CBCT (17). Figure 1 presents the cylindrical waterequivalent phantom (Tough water, Kyoto Kagaku CO., Kyoto, Japan) used to measure the data for this electron density curve. The phantom was $20 \mathrm{~cm}$ in diameter and $19.8-\mathrm{cm}$ long, with a central cylindrical hole of $2.85 \mathrm{~cm}$ in diameter. Rong et al., have reported that the use of a site-specific calibration curve gives a $2 \%$ dose agreement with planning CT plans in phantom studies (18-19). Figure 2 shows the Hounsfield unit-electron density (HU-ED) curves of the CBCT and CT scans.

Mandibular rotation. For the image matching between the planning CT and CBCT during VMAT, we focused on the third and fourth cervical vertebrae. The mandibular rotation angle was measured as a setup error. The difference in the mandibular rotation between the planning $\mathrm{CT}$ and CBCT was measured from the center of the first cervical vertebrae to the mandible edge (Figure 3 ) and the average of the left and right values was defined as mandibular rotation.

Analysis. The re-contoured OARs and target volumes were propagated from the planning $\mathrm{CT}$ to the $\mathrm{CBCT}$ scans using SmartAdapt ${ }^{\circledR}$. Subsequently, the CBCT plans were constructed with
Table I. Treatment characteristics.

\begin{tabular}{lcccc}
\hline Case & $\begin{array}{c}\text { TNM } \\
\text { stage }\end{array}$ & $\begin{array}{c}\text { 7th edition } \\
\text { of UICC stage }\end{array}$ & $\begin{array}{c}\text { Total RT } \\
\text { dose }\end{array}$ & $\begin{array}{c}\text { Concurrent } \\
\text { chemotherapy }\end{array}$ \\
\hline 1 & c3TN2cM0 & IVA & $70 \mathrm{~Gy}$ & CDDP \\
2 & cT2N2bM0 & IVA & $70 \mathrm{~Gy}$ & CDDP \\
3 & cT3N0M0 & III & $70 \mathrm{~Gy}$ & C-mab \\
4 & cT3N2bM0 & IVA & $70 \mathrm{~Gy}$ & C-mab \\
5 & T2N1M0 & III & $70 \mathrm{~Gy}$ & CDDP \\
6 & cT2N2M0 & IVA & $70 \mathrm{~Gy}$ & CDDP \\
7 & cT2N2bM0 & IVA & $70 \mathrm{~Gy}$ & CDDP \\
8 & T3N0M0 & III & $60 \mathrm{~Gy}$ & C-mab \\
9 & T2N0M0 & II & $70 \mathrm{~Gy}$ & CDDP \\
10 & cT1N2bM0 & IVA & $70 \mathrm{~Gy}$ & C-mab \\
\hline
\end{tabular}

CBDCA: Carboplatin; C-mab: cetuximab; m: months.

Table II. The objective parameters used in VMAT optimization.

\begin{tabular}{ll}
\hline Target and risk organs & Dose constraints \\
\hline PTV (normalized at D95) & $\mathrm{D}_{98}>93 \%$ \\
& $\mathrm{D}_{95}=100 \%$ \\
& prescription dose $70 \mathrm{~Gy})$ \\
& $\mathrm{D}_{50}<105 \%$ \\
& $\mathrm{D}_{10}<110 \%$ \\
& $\mathrm{D}_{2}<120 \%$ \\
& \\
Organs at risk & $\mathrm{D}_{\text {max }}<54 \mathrm{~Gy}$ \\
Brain stem (PRV) & $\mathrm{D}_{\text {max }}<50 \mathrm{~Gy}$ \\
Spinal cord (PRV) & $\mathrm{D}_{1 \mathrm{cc}}<46 \mathrm{~Gy}$ \\
& $\mathrm{D}_{\text {mean }}<50 \mathrm{~Gy}$ \\
Optic nerve & $\mathrm{D}_{\text {mean }}<40 \mathrm{~Gy}$ \\
Eyes & $\mathrm{D}_{\text {max }}<6 \mathrm{~Gy}$ \\
Lens & $\mathrm{D}_{\text {mean }}<45 \mathrm{~Gy}$ \\
Inner/middle ear & $\mathrm{D}_{\text {max }}<30 \mathrm{~Gy}$ \\
Oral cavity & $\mathrm{D}_{\text {mean }}<20 \mathrm{~Gy}$ \\
Larynx & $\mathrm{D}_{\text {mean }}<20 \mathrm{~Gy}$ \\
Parotid gland (at least one) & $\mathrm{D}_{\text {mean }}<35 \mathrm{~Gy}$ \\
Submandibular gland (at least one) & $\mathrm{D}_{2}<66 \mathrm{~Gy}$ \\
Mandible &
\end{tabular}

PTV: Planning target volume; PRV: planning organ at risk volume; Dmax: maximum dose; $\mathrm{D}_{\text {mean }}$ : mean dose; $\mathrm{D}_{98}$ : dose to $98 \%$ of the volume; $\mathrm{D}_{95}$ : dose to $95 \%$ of the volume; $\mathrm{D}_{50}$; dose to $50 \%$ of the volume; $\mathrm{D}_{10}$ : dose to $10 \%$ of the volume; $\mathrm{D}_{2}$ : dose to $2 \%$ of the volume; $\mathrm{D}_{1 \mathrm{cc}}$ : dose delivered to a $1 \mathrm{~cm}^{3}$ volume.

dose calculations obtained using HU-ED curves as shown in Figure 2, with the VMAT plans transferred to the CBCT on the basis of matched isocenters and body alignment. An anisotropic analytical algorithm (AAA) was used for the dose calculations of both original and CBCT plans. To obtain a dose-volume histogram (DVH) for the OARs and targets, the CBCT plans were recalculated without optimization.

The image range (z direction) of the CBCT with a TrueBeam linear accelerator (Varian Medical Systems, Inc., Palo Alto, CA, 


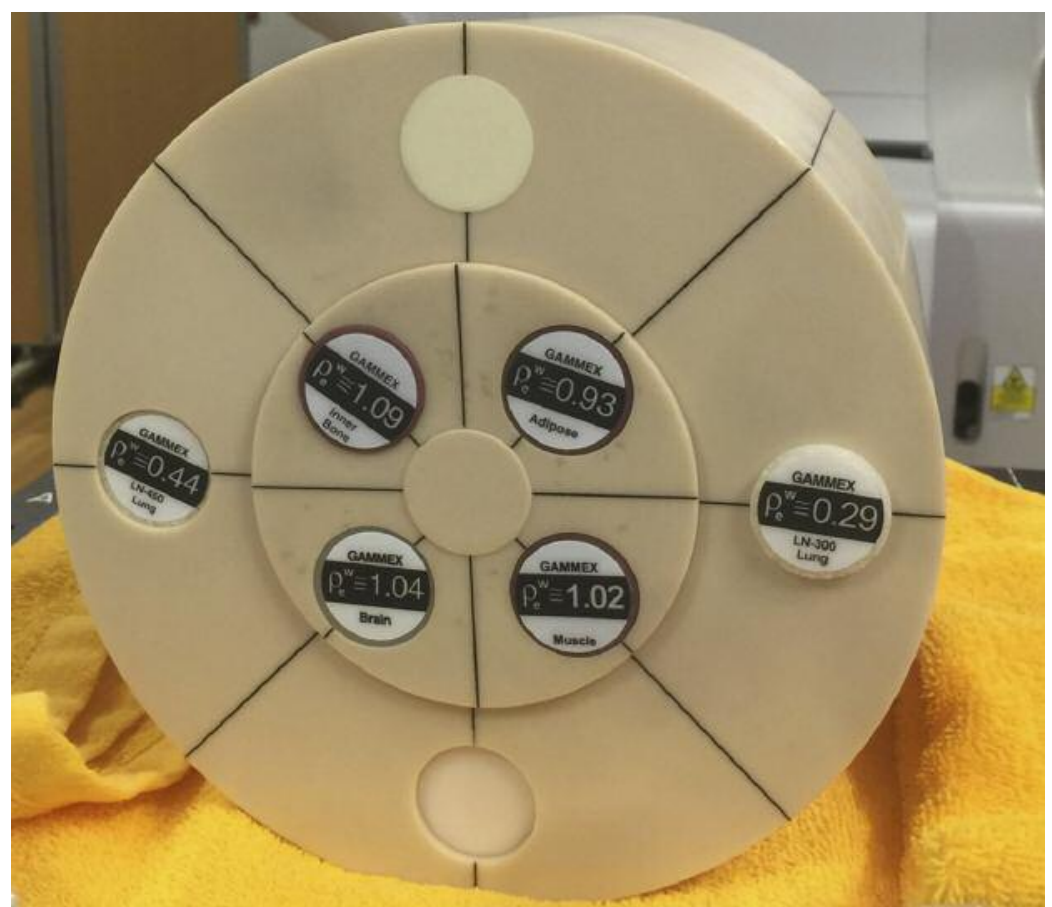

Figure 1. Frontal view of the head phantom used to simulate the head sites for CBCT dose calculation.

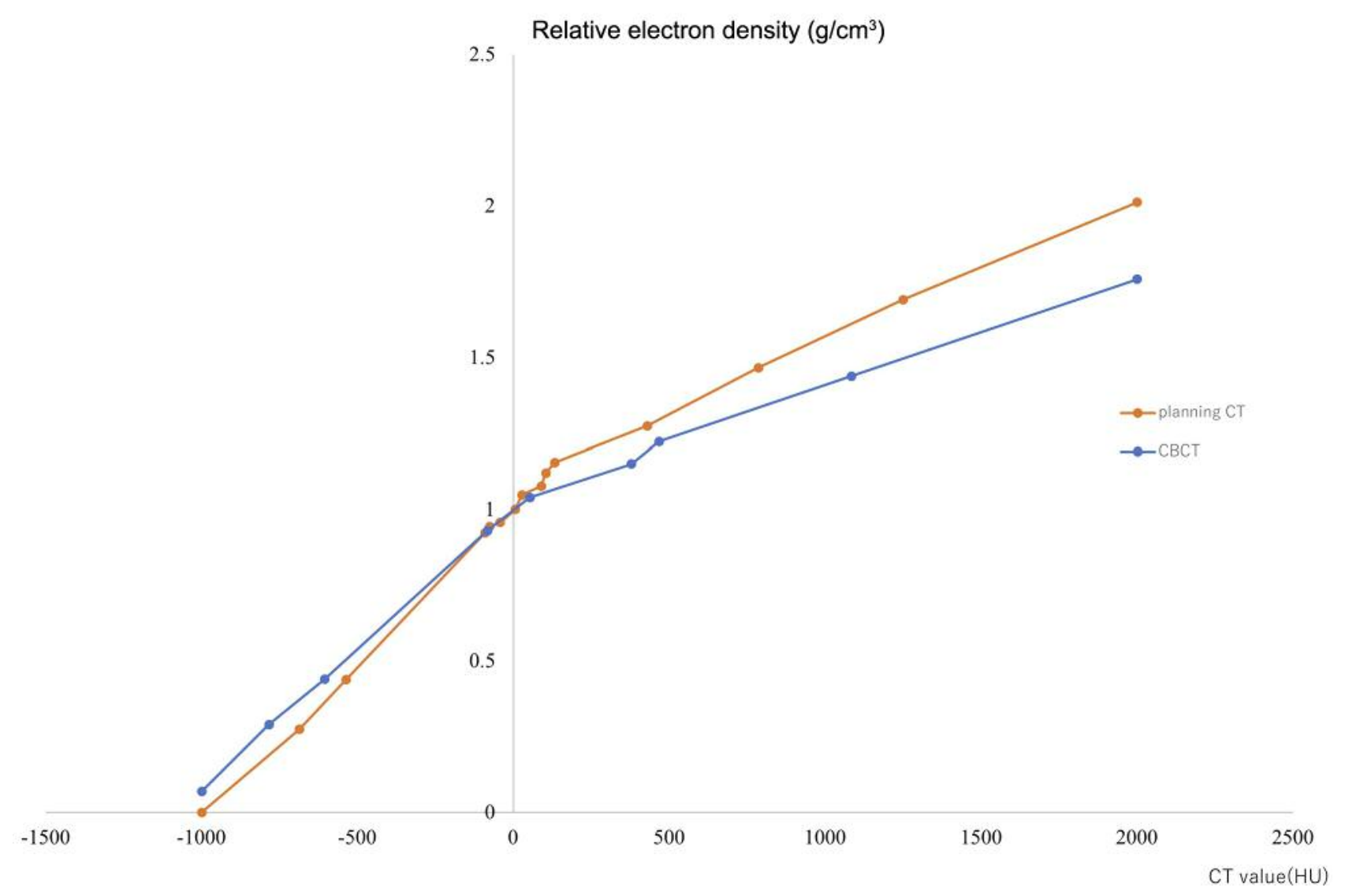

Figure 2. Comparison of HU-ED curves between the CBCT scans (red line) and planning CT (blue line). 


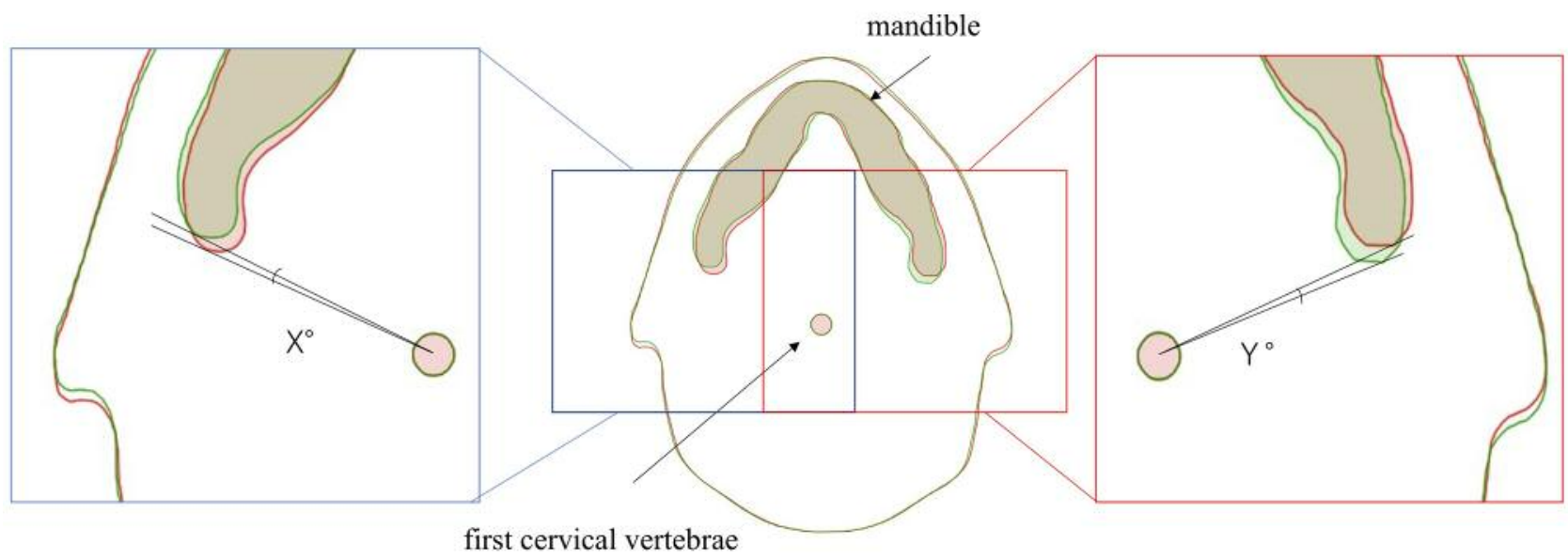

Figure 3. Measurement of the difference in mandibular rotation between the planning CT and CBCT. Mandibular rotation was measured as the difference between the planning CT and CBCT from the center of the first cervical vertebrae to the mandible edge. The green line represents the $C B C T$ image and the red line represents the planning CT image.

USA) is limited to $18.8 \mathrm{~cm}$, while the VMAT treatment range has an average of $19.66 \mathrm{~cm}$ (range 18.5-23.1 cm), which includes the lower neck. We, therefore, evaluated the DVH only within the image range of the CBCT. The weight of the OPC patient was measured every week during the first VMAT period. Weight loss and the rotation of the mandible were measured, and their influence on the dose distribution was investigated.

\section{Results}

The dose difference for the first step VMAT plan and CBCT plans during the first treatment period for the right and left parotid glands are shown in Figure 4A and B, respectively. Figure $4 \mathrm{C}$ and $\mathrm{D}$ show the time trends for weight change and mandibular rotation during the first treatment period, respectively. The dose difference to both parotid glands fluctuated over the course of the treatment is shown in Figure 5. The maximum weight loss was $8.9 \mathrm{~kg}$. Figure $5 \mathrm{~A}$ and $\mathrm{B}$ show the relationship between the weight loss and dose difference for the right and left parotid glands (slopes of -0.1092 and -0.5974 , respectively, with linear regression, and $\mathrm{r}^{2}=-0.079$ and -0.547 ) during the first treatment. Figures 5C and D show the relationship between mandibular rotation and dose difference for the right and left parotid glands (slope of -0.5794 and 0.9226 with linear regression, $\mathrm{r}^{2}=0.1577$ and -0.689 , respectively) during the first VMAT treatment. The mean dose of left parotid glands and mandibular rotation showed no correlation with dose variation. In both mean doses of the right and left parotid glands, mandibular rotation showed a much stronger correlation with dose difference than did weight loss. On the other hand, the variation of dose distribution in PTV was not observed in both factors during the course of radiotherapy.

\section{Discussion}

In this study, an increased likelihood of larger dose variations was shown to be associated with mandibular rotation during the course of radiotherapy. The weight loss is a significant factor changing the dose distribution during the course of IMRT for head and neck cancers, and requires re-planning (20). However, our data revealed unexpected dose changes that could not be explained by weight loss alone and these unexpected dose changes were due to mandibular rotation (Figure 5). The accuracy of the setup was shown to have a greater impact on the dose distribution to the parotid gland compared to weight loss. Castelli et al. described that variation in the mean parotid gland dose was more important between the planning $\mathrm{CT}$ and the $\mathrm{CT}$ for fraction 1 than between each weekly CT (21). This difference may be explained by the delay between the planning CT and the first CBCT. Parotid gland dose differences between the fraction and the initial planning are likely to be related to both setup errors and variations in the volume and shape of anatomical structures. Systematic setup errors may increase the mean parotid gland dose by around $3 \%$ per mm of displacement (21-23).

A highly accurate setup is necessary during VMAT, ideally with the same patient status being maintained throughout the treatment. However, a patient's physical status can dramatically change over the treatment period due to weight loss and/or tumor shrinkage. Such considerable anatomical changes during the course of radiotherapy may lead to suboptimal dosing (20). Bhide et al., have also reported that weight loss and anatomical changes are associated with changes in dose distribution (24). Minimization of the daily setup error could in fact reduce the irradiated doses to the parotid glands, resulting in improvements 
(A) Parotid R

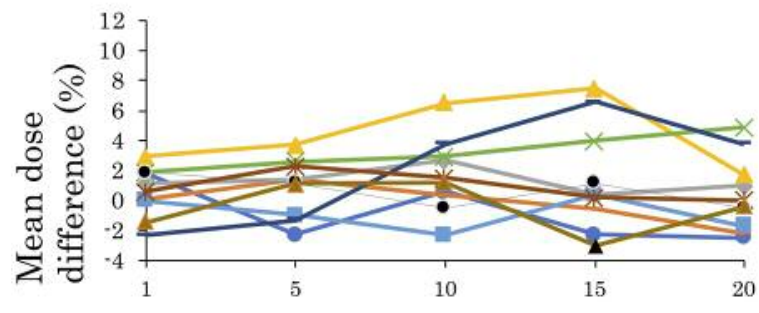

(C) Weight

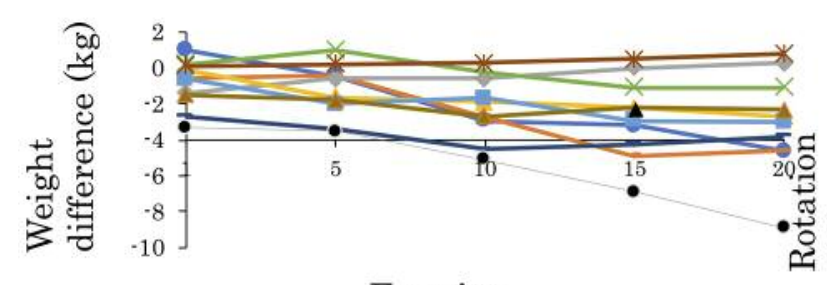

Fraction
(B) Parotid L

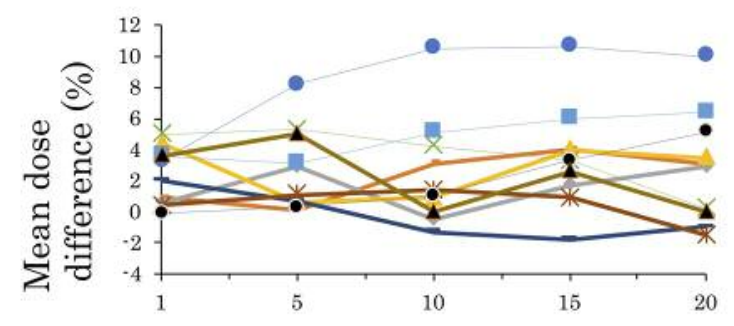

(D) Mandible rotation

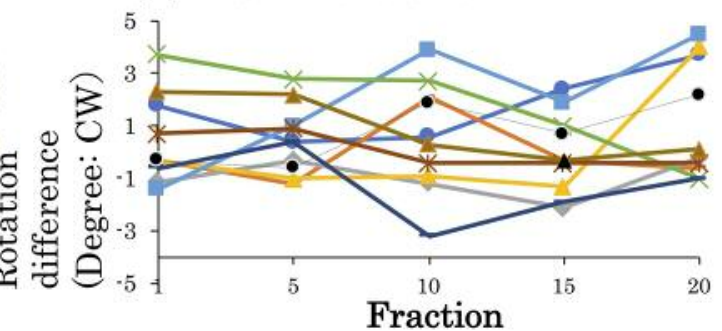

- Case 1

- Case 2

$\multimap$ Case 3

- Case 4

- - Case 5

Case 6

- Case 7

* Case 8

- Case 9

- Case 10

Figure 4. Time trends of the dose differences of the first step of the VMAT and CBCT plans (1, 5, 10 15, and 20 fractions) for right (A) and left parotid gland $(B)$. Time trends of weight $(C)$ and mandibular rotation $(D)$ during the first VMAT.

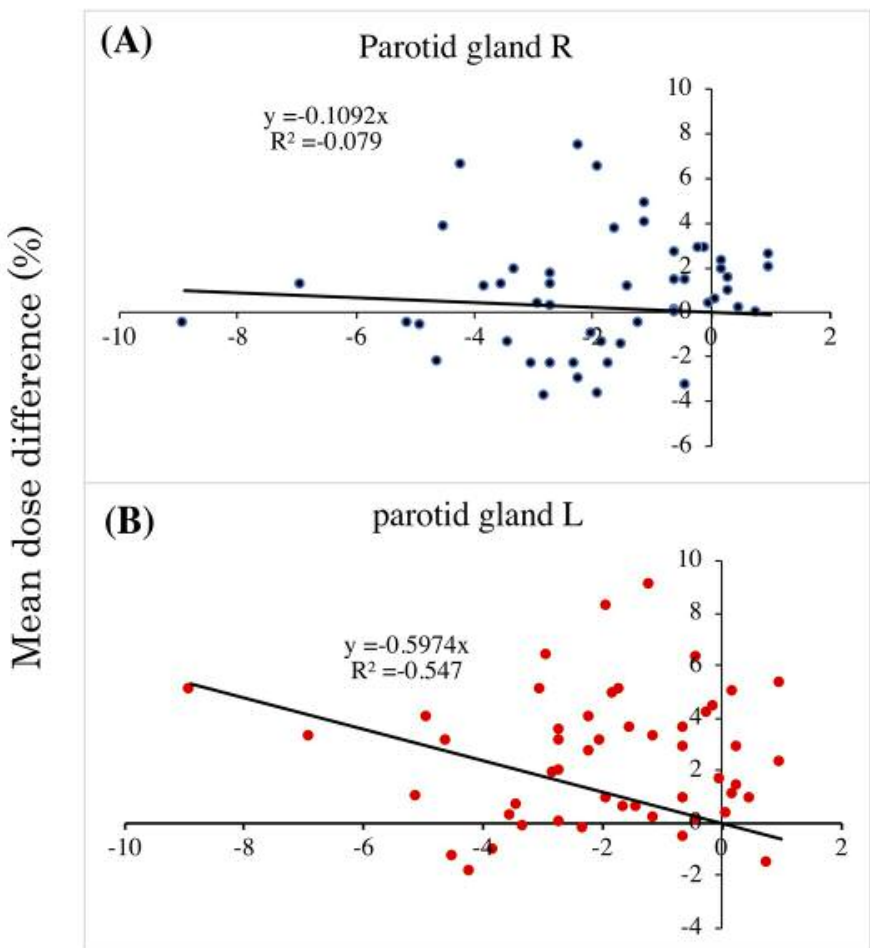

Weight $(\mathrm{kg})$
(C)

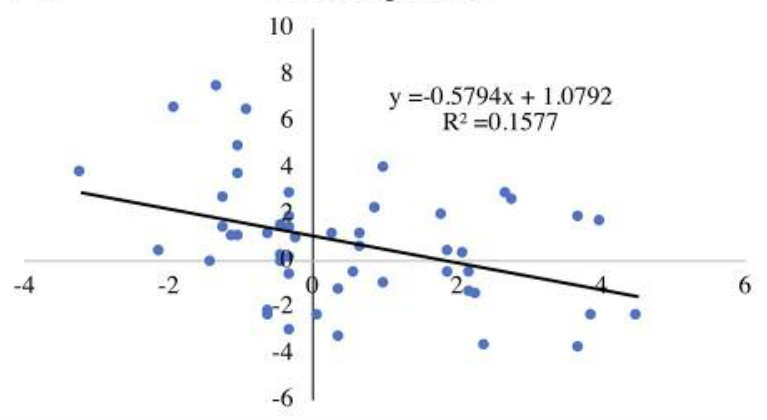

(D)

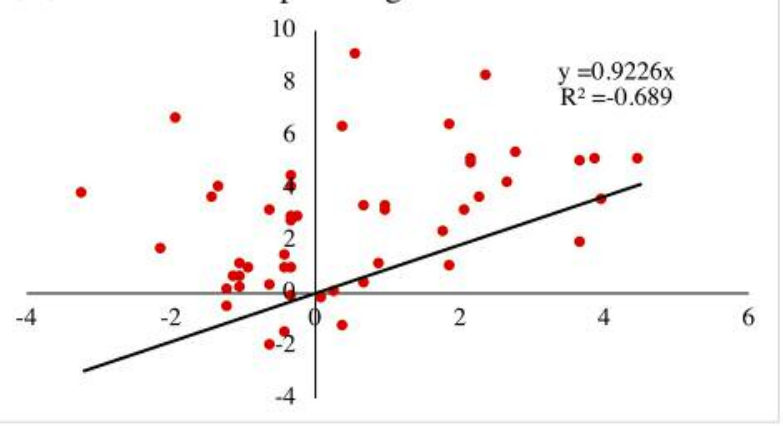

Rotation (degree: CW)

Figure 5. Relationship between weight and dose difference for right $(A)$ and left parotid gland $(B)$ during the first VMAT treatment. Relationship between mandible rotation and dose difference for right $(C)$ and left parotid gland $(D)$ during first VMAT treatment. 
to patients' quality of life and toxicity risk (7). The points suggest that a combination of bone registrations to correct for setup errors and re-planning to correct for anatomical variations is necessary in daily practice.

Knowledge-based planning (KBP), which was developed and released for clinical use (25-27), can reduce the optimization time of re-planning for adaptive radiation therapy. Adaptive radiotherapy is especially important in IMRT and VMAT for head and neck cancers, where the effects of setup errors with respect to unexpected dose distributions are poorly understood. For adaptive radiation therapy using $\mathrm{KBP}$, the patient setup is an important factor for IMRT, with strategies for ensuring accurate patient setup being necessary at CT simulation and during the course of radiotherapy. To provide consistent dose contributions in patients who need adaptive radiotherapy, not only is re-planning required, but also a highly accurate patient setup is major importance.

This study is subject to certain limitations. The CBCT imaging range did not cover the entire treatment areas of the VMAT. Sparing the parotid glands is an important reason for using IMRT (7). Furthermore, this retrospective study includes only a small number of patients with heterogeneous characteristics. Therefore, further prospective CBCT studies covering the entire range of VMAT adaptive treatments are required to establish the ideal fixation and onboard validation methods for head and neck VMAT. In VMAT for OPC, setup is an important factor for both the initial CT simulations and the treatment. Improving the setup can contribute to achieving a highly consistent dose distribution during the entire VMAT treatment course for head and neck cancer.

\section{Conflicts of Interest}

The Authors report no conflicts of interest. The authors are responsible for the content and writing of the paper.

\section{Authors' Contributions}

Concept and design were performed by MO, KI, and HM. Experiments were performed by $\mathrm{MO}$ and $\mathrm{KM}$, data analysis by $\mathrm{MO}$ and HM, and manuscript preparation by MO, MT, HD, YN, and HM. All authors read and approved the final manuscript.

\section{Acknowledgements}

This work was supported by the Japan Society for the Promotion of Science KAKENHI (grant number: 16K10406).

\section{References}

1 Marta GN, Silva V, de Andrade Carvalho H, de Arruda FF, Hanna SA, Gadia R, da Silva JL, Correa SF, Vita Abreu CE and Riera R: Intensity-modulated radiation therapy for head and neck cancer: Systematic review and meta-analysis. Radiother Oncol 110(1): 9-15, 2014. PMID: 24332675. DOI: 10.1016/j.radonc. 2013.11.010
2 Lee N, Xia P, Fischbein N, Akazawa P, Akazawa C and Quivey $\mathrm{J}$ : Intensity-modulated radiation therapy for head-and-neck cancer: the UCSF experience focusing on target volume delineation. Int Radiat Oncol Bio Phys 57(1): 49-60, 2003. PMID: 12909215. DOI:10.1016/S0360-3016(03)00405-X

3 Beadle BM, Liao KP, Elting LS, Buchholz TA, Ang KK, Garden AS and Guadanalo BA: Improved survival using intensitymodulated radiation therapy in head and neck cancers: a SEERMedicare analysis. Cancer 120(5): 702-710, 2014. PMID: 244210477 DOI:10.1002/cncr.28372

4 Barker JL Jr, Garden AS, Ang KK, O'Daniel JC, Wang H, Court LE, Morrison WH, Rosenthal DI, Chao KS, Tucker SL, Mohan $\mathrm{R}$ and Dong L: Quantification of volumetric and geometric changes occurring during fractionated radiotherapy for head-andneck cancer using an integrated CT/linear accelerator system. Int Radiat Oncol Biol Phys 59(4): 960-970, 2004. PMID: 15234029. DOI: $10.1016 /$ j.ijrobp.2003.12.024

5 Hansen EK, Bucci MK, Quivey JM, Weinberg V and Xia P: Repeat CT imaging and replanning during the course of IMRT for head-and-neck cancer. Int J Radiat Oncol Bio Phys 64(2): 355362, 2006. PMID: 16256277. DOI: 10.1016/j.jjrobp. 2005.07.957

6 Pow EK, Kwong DL, McMillan AS, Wong MC, Sham JS, Leung LH and Leung WK: Xerostomia and quality of life after intensity-modulated radiotherapy $v s$. conventional radiotherapy for early-stage nasopharyngeal carcinoma: Initial report on a randomized controlled clinical trial. Int J Radiat Oncol Biol Phys 66(4): 981-991, 2006. PMID: 17145528. DOI: 10.1016/j.ijrobp. 2006.06.013

7 Kam MK, Leung SF, Zee B, Chau RM, Suen JJ, Mo F, Lai M, Ho R, Cheung KY, Yu BK, Chiu SK, Choi PH, Teo PM, Kwan WH and Chan AT: Prospective randomized study of intensitymodulated radiotherapy on salivary gland function in early-stage nasopharyngeal carcinoma patients. J Clin Oncol 25(31): 48734879, 2007. PMID: 17971582. DOI: 10.1200/JCO.2007.11.5501

8 Nishimura Y, Shibata T, Nakamatsu K, Kanamori S, Koike R, Okubo M, Nishikawa T, Tachibana I, Tamura M and Okumura M: A two-step intensity-modulated radiation therapy method for nasopharyngeal cancer: The Kinki University experience. Jpn J Clin Oncol 40(2): 130-138, 2010. PMID: 19841102. DOI: 10.1093/jjco/hyp136

9 Yip C, Thomas C, Michaelidou A, James D, Lynn R, Lei M and Guerrero Urbano T: Co-registration of cone beam CT and planning $\mathrm{CT}$ in head and neck IMRT dose estimation: A feasible adaptive radiotherapy strategy. Br J Radiol 87(1034): 20130532, 2014. PMID: 24288402. DOI: 10.1259/bjr.20130532

10 Li X, Zhang Y, Shi Y, Zhou L, Zhen X and Zhou L: Evaluation of deformable image registration for contour propagation between $\mathrm{CT}$ and cone-beam CT images in adaptive head and neck radiotherapy. Technol Heal Care 12(4): e0175906, 2016. PMID: 28414799. DOI: 10.1371/journal.pone.0175906

11 Hardcastle N, van Elmpt W, De Ruysscher D, Bzdusek K and Tomé WA: Accuracy of deformable image registration for contour propagation in adaptive lung radiotherapy. Radiat Oncol 18(8): 243, 2013. PMID: 24139327. DOI: 10.1186/1748-717X8-243

12 Doi H, Tanooka M, shida T, Moridera K, Ichimiya K, Tarutani K, Kitajima K, Fujiwara M, Kishimoto H and Kamikonya N: Utility of intraoral stents in external beam radiotherapy for head and neck cancer. Rep Pract Oncol Radiother 22(4): 310-318, 2017. PMID: 28515675. DOI: 10.1016/j.rpor.2017.03.002 
13 Doi H, Uemoto K, Masai N, Tatsumi D, Shiomi H and Oh RJ: Definitive re-irradiation using intensity-modulated radiation therapy in cancers of the head and neck, focusing on rare tumors. Acta Otolaryngol 138(8): 750-758, 2018. PMID: 29468910. DOI: 10.1080/00016489.2018.1438662

14 Tanooka M, Doi H, Ishida T, Kitajima K, Wakayama T, Sakai T, Inoue $\mathrm{H}$, Kotoura $\mathrm{N}$, Kosaka $\mathrm{K}$, Tarutani $\mathrm{K}$, Fujiwara $\mathrm{M}$ and Kamikonya N: Usability of deformable image registration for adaptive radiotherapy in head and neck cancer and an automatic prediction of replanning. IJMPCERO 6(1): 10-20, 2017. DOI: 10.4236/ijmpcero.2017.61002

15 Su J, Chen W, Yang H, Hong J, Zhang Z, Yang G, Li L and Wei $\mathrm{R}$ : Different setup errors assessed by weekly cone-beam computed tomography on different registration in nasopharyngeal carcinoma treated with intensity-modulated radiation therapy. Onco Targets Ther 14(8): 2545-2553, 2015. PMID: 26396530. DOI: 10.2147/ OTT.S87159

16 Tatebe H, Doi H, Ishikawa K, Kawakami K, Yokokawa M, Nakamatsu K, Kanamori S, Shibata T, Kitano M and Nishimura Y: Two-step intensity-modulated radiation therapy for oropharyngeal cancer: initial clinical experience validation of clinical staging. Anticancer Res 38(2): 979-986, 2018. PMID: 29374730. DOI: 10.21873 /anticanres.12312

17 Rong Y, Smilowitz J, Tewatia D, Tomé WA and Paliwal B: Dose calculation on $\mathrm{kV}$ cone beam CT images: an investigation of the Hu-density conversion stability and dose accuracy using the sitespecific calibration. Med Dosim 35(3): 195-207, 2010. PMID: 19931031. DOI: 10.1016/j.meddos.2009.06.001

18 Elstrøm UV, Olsen SRK, Muren LP, Petersen JBB and Grau C: The impact of CBCT reconstruction and calibration for radiotherapy planning in the head and neck region - a phantom study. Acta Oncol 53(8): 1114-1124, 2014. PMID: 24975372. DOI: $10.3109 / 0284186 X .2014 .927073$

19 Dunlop A, McQuaid D, Nill S, Murray J, Poludniowski G, Hansen VN, Bhide S, Nutting C, Harrington K, Newbold K and Oelfke U: Comparison of CT number calibration techniques for CBCT-based dose calculation. Strahlenther Onkol 191(12): 970978, 2015. PMID: 26403913. DOI: 10.1007/s00066-015-0890-7

20 Nishi T, Nishimura Y, Shibata T, Tamura M, Nishigaito N and Okumura M: Volume and dosimetric changes and initial clinical experience of a two-step adaptive intensity modulated radiation therapy (IMRT) scheme for head and neck cancer. Radiother Oncol 106(1): 85-89, 2013. PMID: 23337058. DOI: 10.1016/ j.radonc.2012.11.005
21 Castelli J, Simon A, Louvel G, Henry O, Chajon E, Nassef M, Haigron P, Cazoulat G, Ospina JD, Jegoux F, Benezery K and de Crevoisier R: Impact of head and neck cancer adaptive radiotherapy to spare the parotid glands and decrease the risk of xerostomia. Radiat Oncol 9(10): 6, 2015. PMID: 25573091. DOI: $10.1186 / \mathrm{s} 13014-014-0318-\mathrm{Z}$

22 Castadot P, Lee JA, Parraga A, Geets X, Macq B and Grégoire $\mathrm{V}$ : Comparison of 12 deformable registration strategies in adaptive radiation therapy for the treatment of head and neck tumors. Radiother Oncol 89(1): 1-12, 2008. PMID: 18501456. DOI: $10.1016 /$ j.radonc.2008.04.010

23 Hirose Y, Nakamura M, Tomita T, Kitsuda K, Notogawa T, Miki $\mathrm{K}$, Nakamura $\mathrm{K}$ and Ishigaki T: Evaluation of different set-up error corrections on dose-volume metrics in prostate IMRT using CBCT images. J Radiat Res 55(5): 966-975, 2014. PMID: 24820094. DOI: $10.1093 /$ jrr/rru033

24 Bhide SA, Davies M, Burke K, McNaiir HA, Hansen V, Barbachano Y, El-Hariry IA, Newbold K, Harrington KJ and Nutting CM: Weekly volume and dosimetric changes during chemoradiotherapy with intensity-modulated radiation therapy for head and neck cancer: a prospective observational study. Int J Oncol Biol Phys 76(5): 1360-1368, 2010. PMID: 20338474. DOI: $10.1016 /$ j.ijrobp.2009.04.005

25 Chanyavanich V, Das SK, Lee WR and Lo JY: Knowledge-based IMRT treatment planning for prostate cancer. Med Phys 38(5): 2515-2522, 2011. PMID: 21776786. DOI: 10.1118/1.3574874

26 Kubo K, Monzen H, Ishii K, Tamura M, Kawamorita R, Sumida I, Mizuno $\mathrm{H}$ and Nishimura $\mathrm{Y}$ : Dosimetric comparison of RapidPlan and manually optimized plans in volumetric modulated arc therapy for prostate cancer. Phys Medica 44: 199204, 2017. PMID: 28705507. DOI: 10.1016/j.ejmp.2017.06.026

27 Ueda Y, Fukunaga J, Kamima T, Adachi Y, Nakamatsu K and Monzen H: Evaluation of multiple institutions' models for knowledge-based planning of volumetric modulated arc therapy (VMAT) for prostate cancer. Radiat Oncol 13(1): 46, 2018. PMID: 29558940. DOI: 10.1186/s13014-018-0994-1

Received April 24, 2019

Revised May 27, 2019

Accepted May 28, 2019 